\title{
FULL SCALE NEAR SURFACE WATER PARTICLE VELOCITIES AND PRESSURES ACTING ON AN INCLINED TABULAR MEMBER
}

\section{BY \\ FRITZ BÜSCHING AND ECKEHARD MARTINI}

DIVISION OF HYDRODYNAMICS AND COASTAL ENGINEERING TECHNICAL UNIVERSITY OF BRAUNSCHWEIG, WEST GERMANY

Reprint from the Proceedings of the 17 th INTERNATIONAL CONFERENCE ON COASTAL ENGINEERING Sydney, AUSTRALIA, March 1980 as published by the American Society of Civil Engineers 


\title{
FULL SCALE NEAR SURFACE WATER PARTICLE VELOCITIES AND PRESSURES ACTING ON AN INCLINED TUBULAR MEMBER
}

\author{
by \\ Fritz Busching 1) and Eckehard Martini ${ }^{2)}$
}

\begin{abstract}
A field investigation programme on simultaneous wave force and water particle velocity measurements is decribed with reference to an inclined fubular member subjected to offshore wave kinematics. First measurements at supercritical

Reynolds numbers indicate strong irregularities in successively raken pressure distributions on the circumference of the test section as well as in the velocity vectors.

The influence of superimposed tidal currents is obvious.
\end{abstract}

\section{INTRODUCTION}

For want of anything better, MORISON's equation is still used for the calculation of wave forces on circular cylindrical structural members. Most experiments are based on it both in the laboratory and in the field. However, usually only water level deflexions and wave forces on a fest section are measured, and the velocities and accelerations as input to MORISON's equation are determined using some suitable wave theory. As is well known, this procedure turns out to be one of the reasons for the wide range of scatter in the reported force coefficients.

Contrary to the respective investigation technique, DEAN (1976) pointed out the necessity of also measuring undisfurbed flow characteristics down in the fluid. KIM and HIBBARD (1975) measured the local water particle velocities in a full scale experiment and similar measurements are being carried out at present in the Christchurch Bay Tower experiment, see for instance PEARCY and BISHOP (1979) and HOLMES and TICKELL (1979).

High enough REYNOLDS's numbers in the laboratory experiments to be applicable to prototype were only obtained by applying special model techniques for instance SARPKAYA (1976), HOGBEN (1976), YAMAMOTO and NATH (1976).

It remains, however, still a question as to how well the laboratory results apply to real wave motion, and especially to irregular waves with varying directions of propagation.

1) Chief-Engineer, Dr.-ing. ; 2) Dipl.-Ing. Div. of Hydrodyn, and Coastal Eng. Techn. Univ.Braunschweig, F.R.G. 
Being also aware of additional uncertainties arising from

a) different roughness characteristics due to marine fouling,

b) the coincident presence of waves and (tidal and wind induced) currents,

c) different shapes of test sections (vertical or inclined),

d) different wave kinematics (deep versus shallow water) etc.

the authors initiated a field wave force investigation programme which is sponsored by the GERMAN MINISTRY OF RESEARCH AND TECHNOLOGY (project number MTK 0053).

The experiments are performed on the GERMAN RESEARCH PLATFORM "Nordsee" about $100 \mathrm{~km}$ offshore in a water depth of approx. $30 \mathrm{~m}$. There is also another measuring programme under way on the island of NORDERNEY (German North Sea Coast) involving substantially differing kinematics of shallow waves.

Both investigation programmes are at first restricted to the measurement of near surface wave forces (derived from the measured pressure distribution on the circumference of tubular members), water level deflexions (woves) and to the measurement and analysis of the ambient flow characteristics including tidal, wind and wave induced currents.

In the future the research programmes will be extended by the measurement of directional spectra (from an array of 3 sonar devices) in the offshore programme and the near shore measuring configuration shall be combined with measurements of additional forces exerted by wave spray loadings, see FÜHRBÖTER (1977).

At present the MTK-project deals with the wave loadings exerted on an inclined member of a platform leg, and the nearshore measuring configuration consists of a vertical pile structure for the force measurement with a satellite measuring station for the measurement of water level deflexions and particle velocities.

Because of the lack of space, only the offshore measuring configuration is described in the following including the test structure, the measuring devices, some data processing routines and preliminary evaluations are outlined. Additional remarks on the near shore measuring configuration are contained in BUSCHING, MARTINI and SPARBOOM (1979).

\section{MEASURING CONFIGURATION}

The measuring devices of the test section (Fig. 1) consist of a packing ring clamped on a member of a platform leg which is inclined $30.225^{\circ}$ with reference to the vertical axis. This tubular structure $(5 \mathrm{~m}$ long, $1.92 \mathrm{~m}$ diameter) containes $24 \mathrm{KISTLER-pressure} \mathrm{transducers} \mathrm{on} \mathrm{its} \mathrm{circumference}$ centered about $5 \mathrm{~m}$ below mean low water spring (MLWS). 


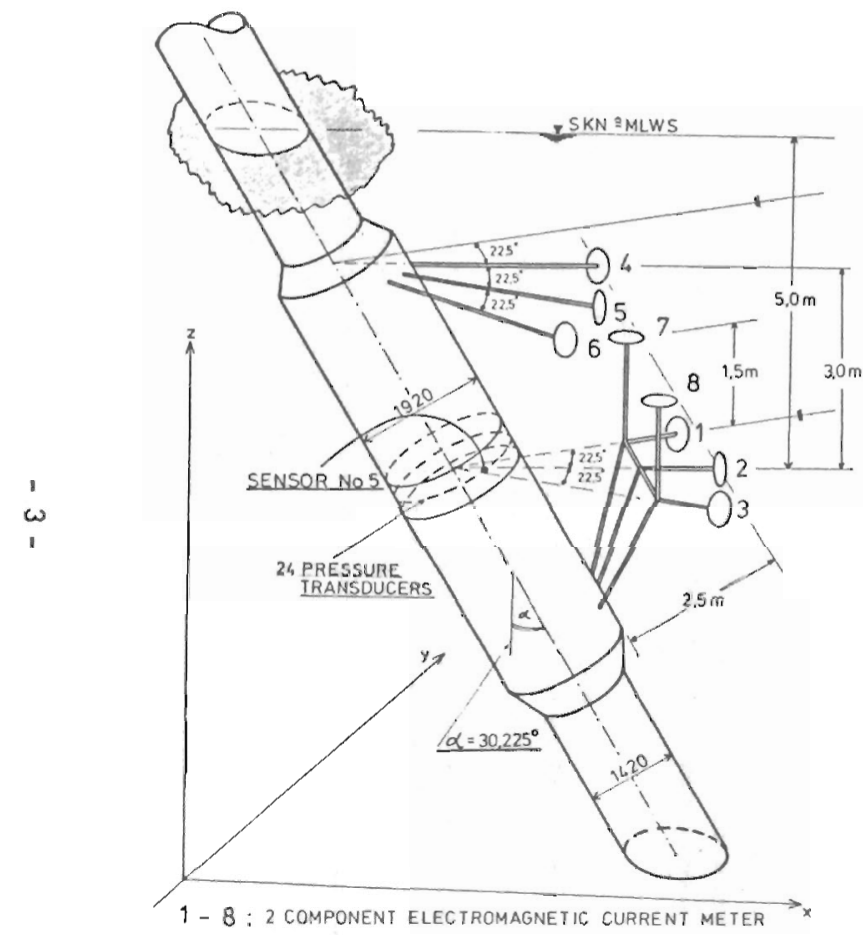

Fig. 1 : Sketch of the measuring configuration

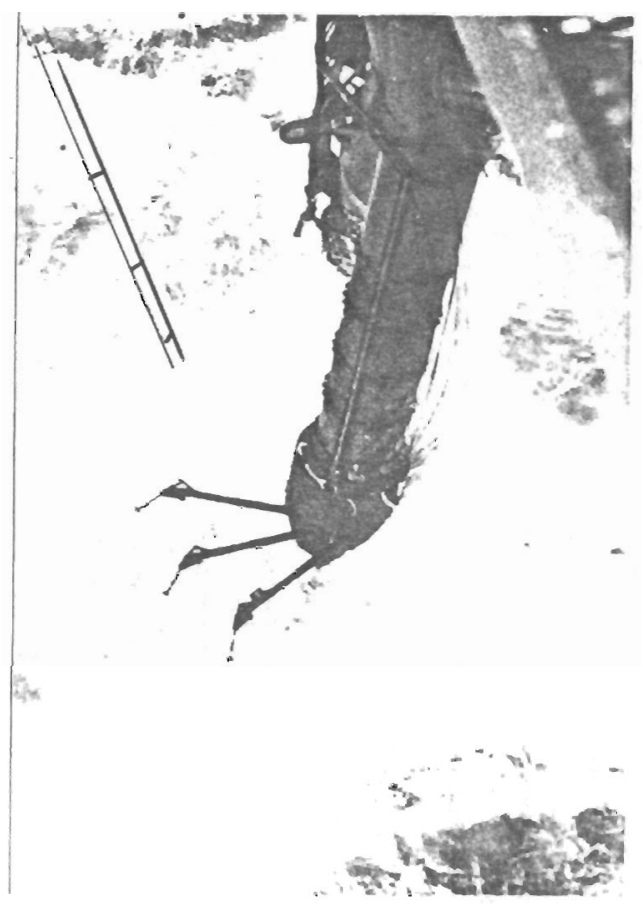

Fig. 2 : Test section clamped on an inclined member of the platform substructure to be seen al an extremely low tide water level at storm condition:. Baylor wave staff on the left hand side. 
At the same elevation are localed 3 two-component electromagnetic COLNBROOK-current meters (No. 1 - 3) oriented in such a way (angular spaced $22.5^{\circ}$ and $2.5 \mathrm{~m}$ distant from the test section) that the particle velocities in certain vertical planes containing the respective main wave propagation direction can be determined from the measurements to a high degree of reliability. For the direct measurement of the wave propagation direction and the phase velocities, the current meters No. 7 and 8 are used, each measuring two velocity components in a horizontal plane $3.5 \mathrm{~m}$ below MLWS.

Additionally only $2 \mathrm{~m}$ below MLWS, there is a third horizontal measuring plane again containing 3 current meters (No.4, 5 and 6) for another measurement of the water particle kinematics in vertical planes with reference to the above mentioned current meter positions No. 1, 2 and 3 .

The corresponding water level deflexions are measured at a certain distance from the test section by a BAYLOR wave staff, see Fig. 2. Additional wave dato can also be received from a set of 3 sonar devices fixed to different members of the platform structure, see LONGREE (1976).

\section{MEASUREMENTS}

Because of the many interpretation difficulties arrising due to the inclination of the tubular member, superimposed currents and reflexion effects (resulting from the neighbouring platform substructure elements) etc. the authors found it to be reasonable as an initial attempt at data interpretation to consider the simplest loading case in which the main wave propagation direction is in the vertical plane of the inclined member.

As can be seen from Fig. 3, such a configuration occurs when wind and waves come from south westerly directions which unfortunately are not in correspondence with the direction of maximum reliability of current meters 1 - 6 measuring rotating orbital vectors in vertical planes. Hence, the description of actual force creating wave kinematics can only be based on the measurement of

the water level deflexions,

the pressure distribution on the circumference and

the horizontal velocity components (of current meters No. 7 and 8), which are most reliable for maximum values only.

As an example, such an irregular wave trace measured by the BAYLOR wave staff on November 15th, 1978, 10.11 p.m. at a distance of about $2 \mathrm{~m}$ from the test section is shown in the upper part of Fig. 4, and the total set of synchronously taken pressure traces from the circumference of the test section is shown below. Additionally Fig. 5 and 6 contain the corresponding velocity traces of current meters No. 7 and 8 respectively each split into magnitude and direction. All of these traces cover a measuring period of $12.8 \mathrm{sec}$ which are sampled at intervalls of $0.2 \mathrm{sec}$ giving 64 phase points also indicated in the graphs. 


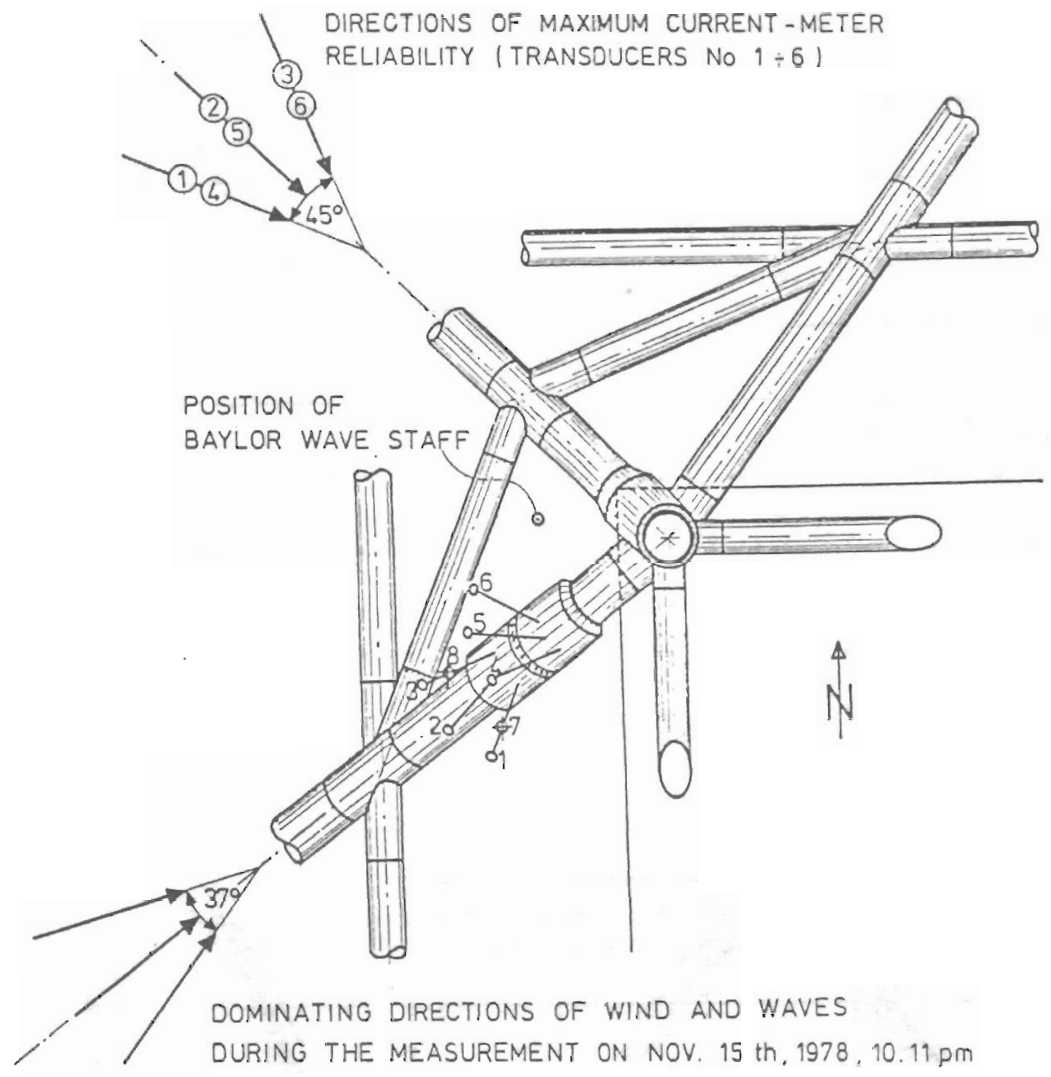

Fig. 3: Orientation of the test section with reference to different directions of wave propagation

The pressure measurements shown in Fig. 4 do not contain any different hydrostatic components corresponding to their respective location below the water level. Hence, the zero mark shown is arbitrary only. The different behaviour of the curves is due to the processes taking place in the boundary layer at specific transducer locations on the circumference and depends on the actual wave propagation direction. This is examined in detail in Fig. 7 showing the pressure distributions (on the circumference of the test section) corresponding 

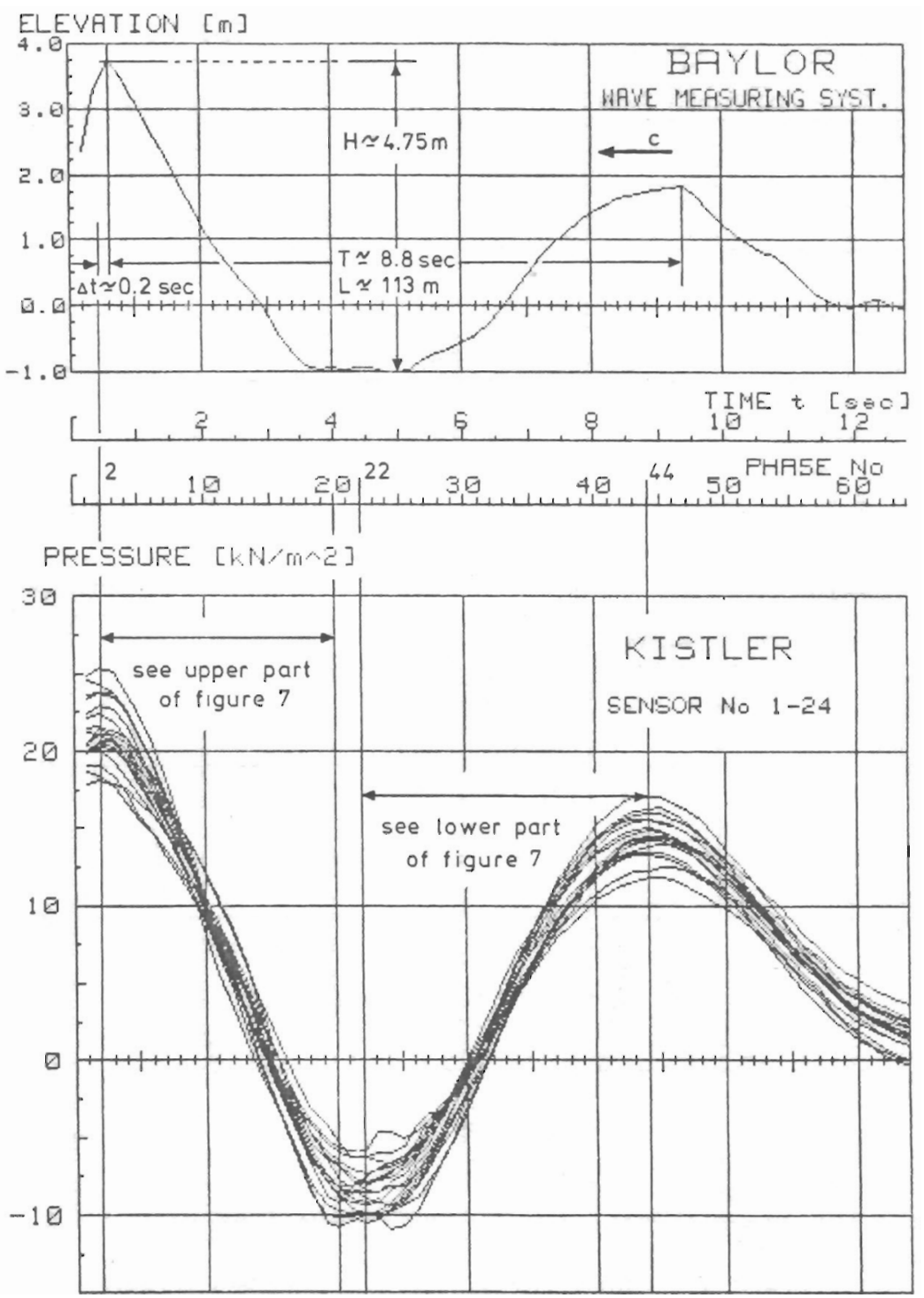

Fig. 4: Synchronously measured wave trace and pressure traces on the test section circumference on November 15th, 1978, $10.11 \mathrm{pm}$ 


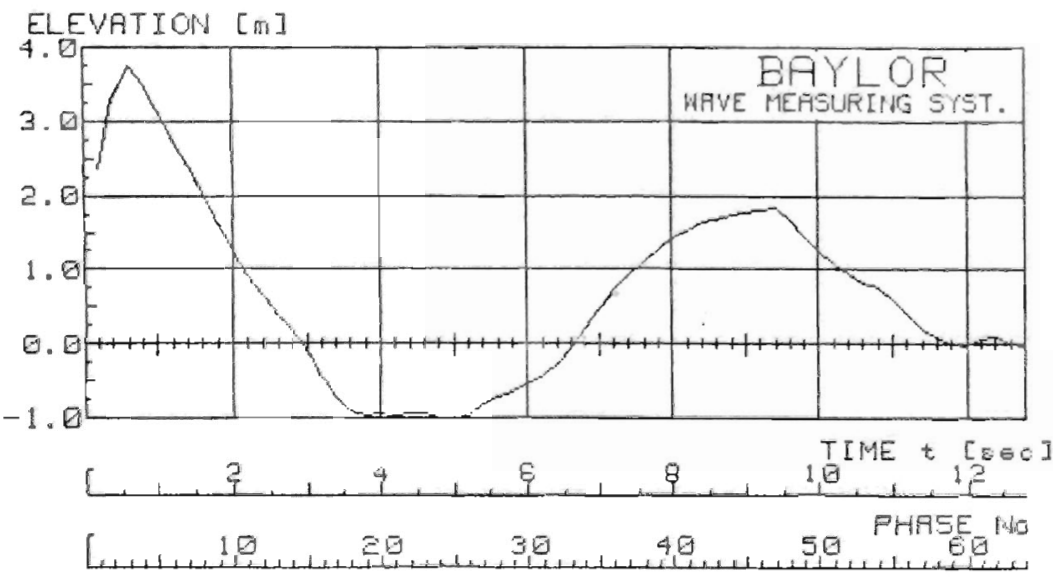

MAGNITUDE $v[\mathrm{~m} / \mathrm{sec}]$

DIRECT.

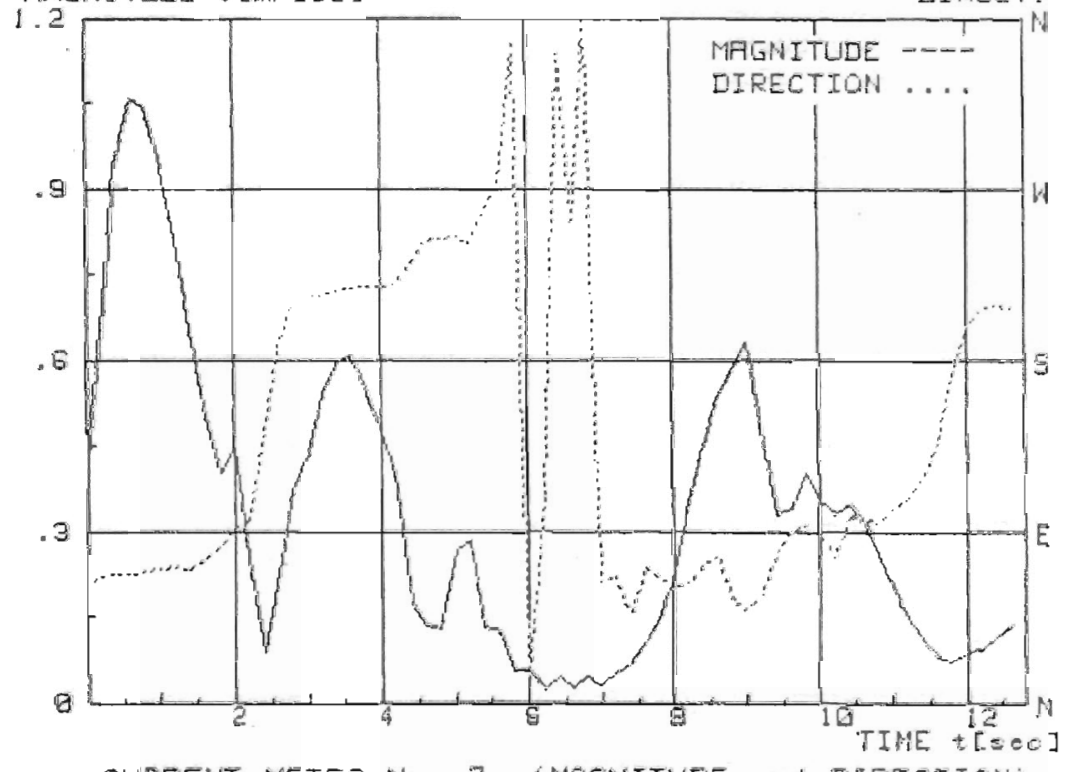

CURRENT-METEP NO:? (MAGNITUDE and DIRECTION)

Fig. 5: Synchronously measured wave and velocity traces on November 15th, 1978, $10.11 \mathrm{pm}$ 


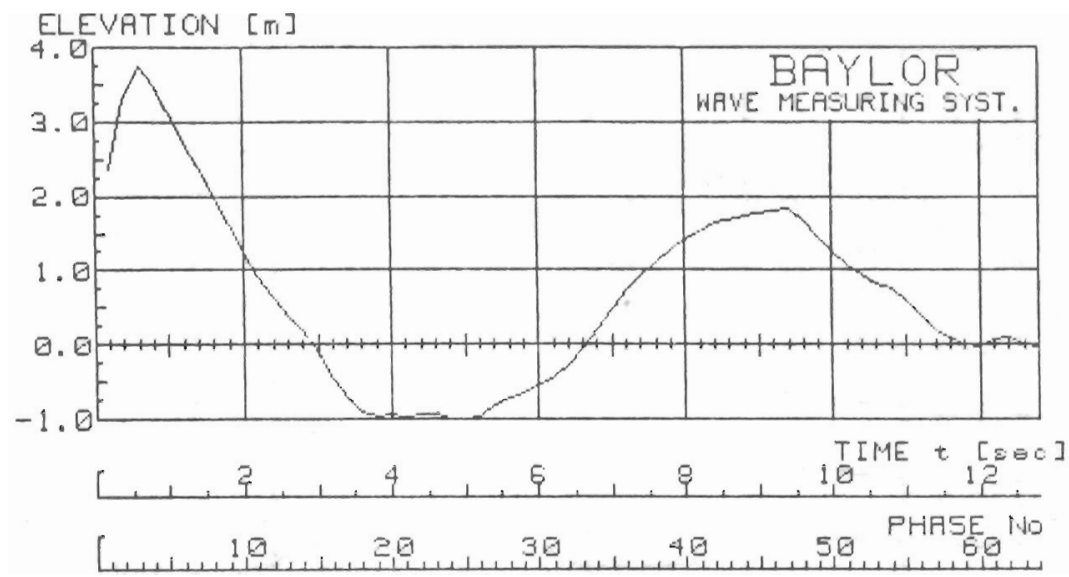

MAGNI TUDE $v[\mathrm{~m} / \mathrm{sE}]$

DIRECT.

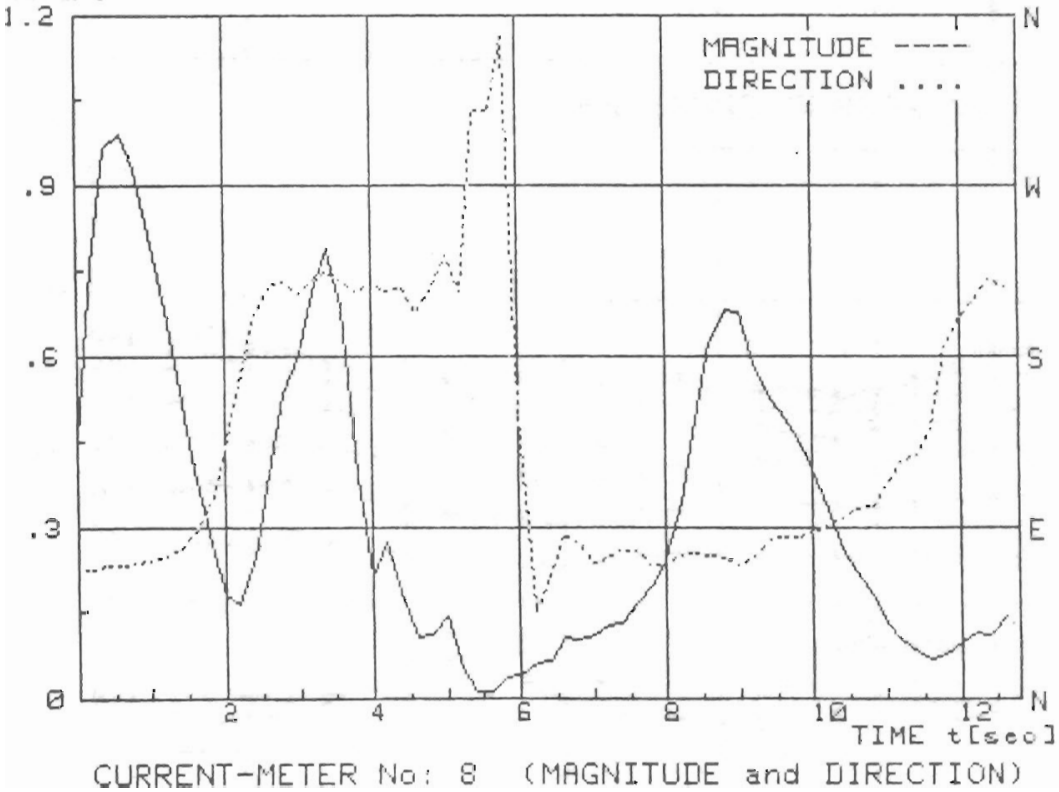

Fig. 6: Synchronously measured wave and velocity traces on November 15th, 1978, $10.11 \mathrm{pm}$ 
PRESSIJRES [KN/m^2]

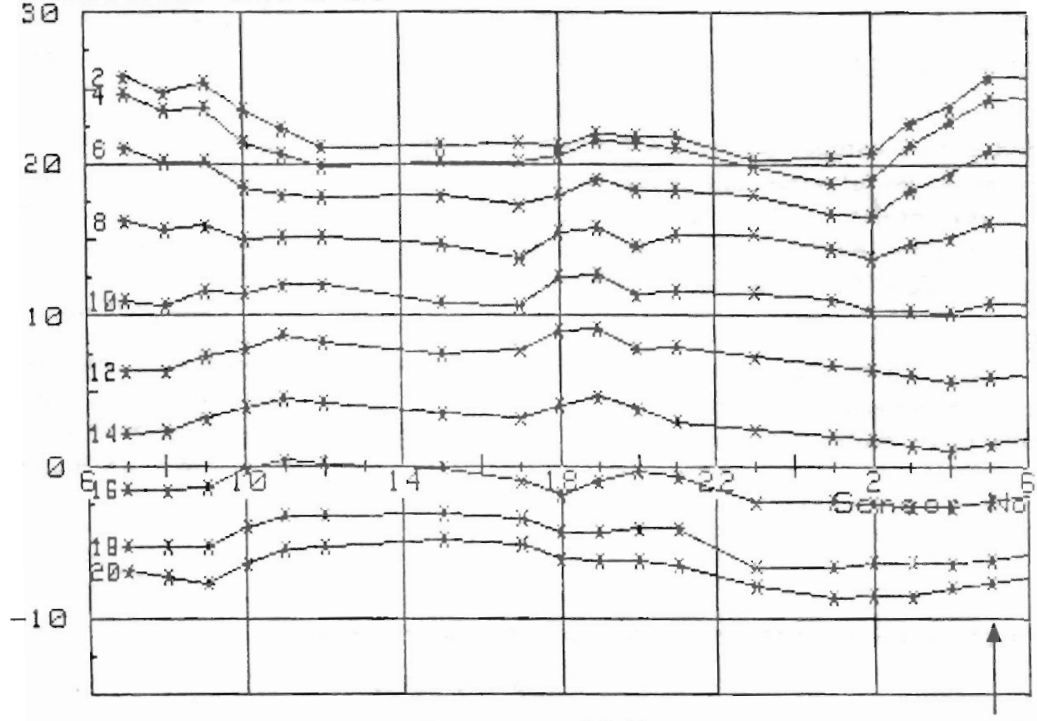

PRESSLRES [KNmZ] PRESSURE SENSOR NO. 5

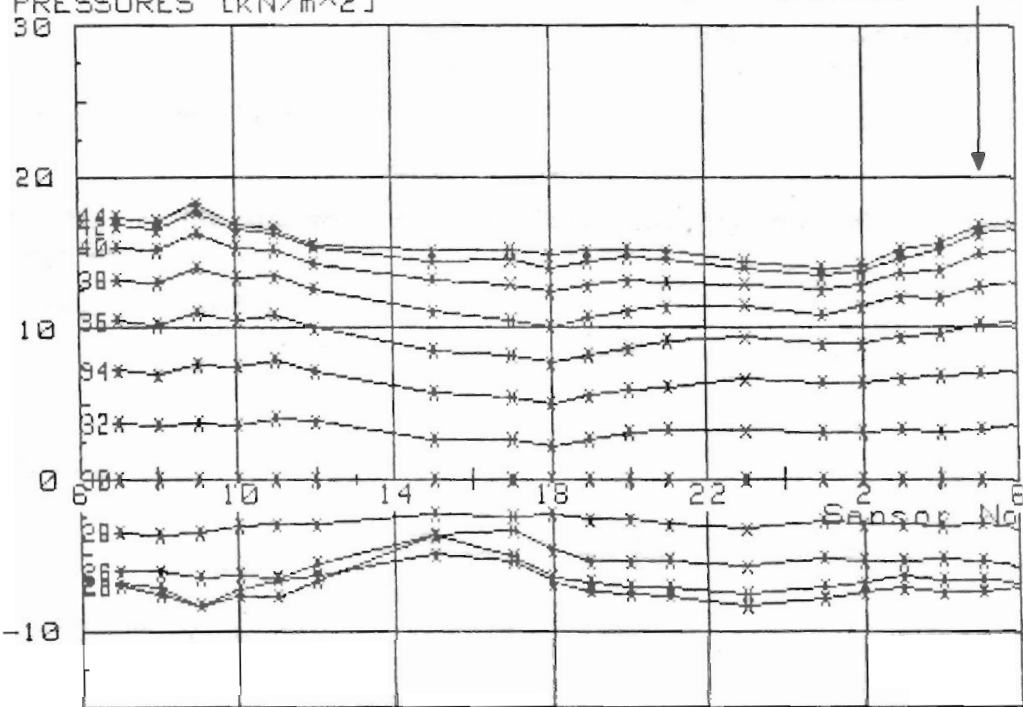

Fig. 7: Variation of pressure distributions on the circumference of the test section with wave phase 
to phase intervalls of $0.4 \mathrm{sec}$. The respective development from phase No. 2 to No. 20 (marked by numbers on the left hand side), is shown in the upper part of this Fig. and the measurements corresponding to phase numbers 22 to 44. are shown below.

For example, pressure sensor No. 5 (indicated by arrows) located at the highest point on the circumference (see also Fig. 1) shows the absolute maximum pressure value near the first wave crest position (phase No. 2), intermediate values (with respect to other transducers) corresponding to trough phase numbers 18 to 26 and comes back to a relatively high value at the next crest position (phase No.44).

Because of erroneous offsets in some of the transducer signals in this case all the distributions refer to that of phase no. 30 whose raw data showed minimum deviations from zero. As a consequence in this kind of presentation its pressure values are zero everywhere, cf. lower part of Fig. 7.

\section{CONCLUSIONS}

With the vertical distance between the first wave crest and the following trough

$$
H \simeq 4.75 \mathrm{~m}
$$

and the time between the two crests

$$
\begin{array}{ll}
T \simeq 8.8 \mathrm{sec} & \text { corresponding to a wave length } \\
L \simeq 113 \mathrm{~m} & \text { (at a water depth of about } 30 \mathrm{~m} \text { ) }
\end{array}
$$

both taken from Fig. 4 and

$$
\max . u_{c}=1 \mathrm{~m} / \mathrm{sec}
$$

from Fig. 5, the data may be characterized roughly by calculating the following. quantities :

REYNOLDS's number

$$
R_{n}=\frac{\max u_{c} \cdot D}{\nu} \simeq \frac{1 \cdot 1.92}{10^{-6}}=1.92 \cdot 10^{6}
$$

KEULEGAN-CARPENTER number

$$
N_{K C}=\frac{\max u_{C} \cdot T}{D} \simeq \frac{1 \cdot 8.8}{1.92}=4.58 \text { and }
$$

DEANS's reliability ratio (cf. DEAN (1976) Fig. 5)

$$
R_{D}=\frac{F_{D \text { max }}}{F_{J_{\text {max }}}} \approx 0.4
$$


Hence, at least of the wave crest position the conditions are well within the rough turbulent flow regime and the data turn out to be more appropriate for extracting $C_{M}$ rather than $C_{D}$. Because of the unsufficient velocity measurement, however, at the present stage the authors do not find it reasonable to apply routines for extracting any force coefficients until the actual flow pattern around the inclined member can be described in general and particularly with ieference to varying directions of wave propagation. The following remarks contribute to that aim.

Although there arestrong irregularities to be seen from the pressure distributions in Fig. 7, a certain similarity to the well known supereritical stationary flow case is obvious. This is most distinct of the wave crest position (phase no 2) with maximum pressures at the front face and a secondary pressure maximum on the opposite side of the test section circumference. With the flow direction changing the secondary pressure maximum becomes the absolute maximum (near sensor numbers 15 and 17 at phase numbers 22 and 24 respectively) and vice versa, however with its exact location changing from wave to wave.

After integrating the pressure distributions (at phase intervalls of $0.2 \mathrm{sec}$ ), the irregular behaviour can also be observet in the resultant force vectors which are plotted with the wave phase in the two alternative presentations of Fig. 8.

The irace of successive force vectors is shown in the upper part and the same data are given below with reference to 0 . Both traces are numbered consecutively.

Up to phase number 8 the forces are directed easterly and have south-westerly components at phases to 30 .

Maximum forward and backward force vectors differ by angles of $\alpha=69^{\circ}$ and $B=91^{\circ}$ respectively (see lower part of Fig. 8). A similar change can be seen from the following wave cycle. An inspection of the velocity data is helpful in order to check as to how much these changing force directions are influenced by the inclination of the tubular member.

The respective presentations - similar to that of the resultant forces - are shown in Fig. 9 and 10 respectively. It is apparent from these graphs that there also exist differences in the forward and backward directed flow, but the difference angles between maximum velocities (most reliably measured) are in the range of $13^{\circ}$ to $30^{\circ}$ only (see upper part of Fig. 9).

A speculation that the deviations are due to superimposed currents can be true, if tidal velocities are considered:

As an example Fig. 11 shows the behaviour of the tidal currents at the same location as during the measuring period from February 15th to 20th, 1977. In particular it can be seen from this graph that maximum tidal velocities (1 hour average values) occur with magnitudes of about $V_{T} \approx 0.3 \mathrm{~m} / \mathrm{sec}$ setting easterly at increasing water levels and north-westerly with the water level decreasing. By inserting the vectors $U_{C R}$ and $U_{T R}$ from Fig. 9 into Fig. 11 at a tide phose similar to that of the measurements on November 15th, 1978, the asymmetry between $U_{T R}$ and $U_{C R}$ can be explained by a superimposed tidal current of $V_{T} \simeq 0.3 \mathrm{~m} / \mathrm{sec}$. The even stronger asjmmetry in the force vectors of Fig. 8 than in the velocity vectors (of Fig. 9 and 10) is because an inclined member 

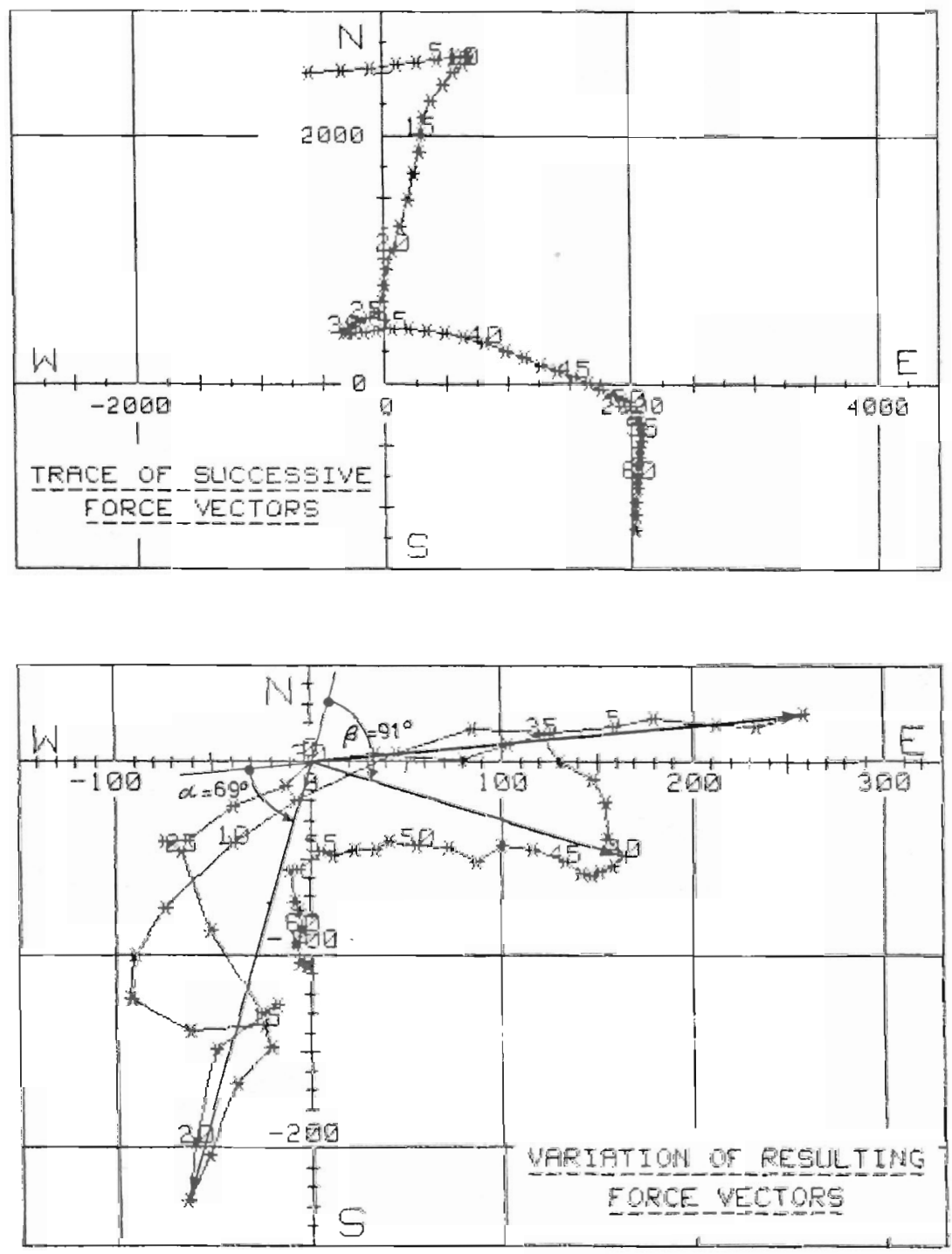

Fig. 8: Variation of resultant force vectors with wave phase 


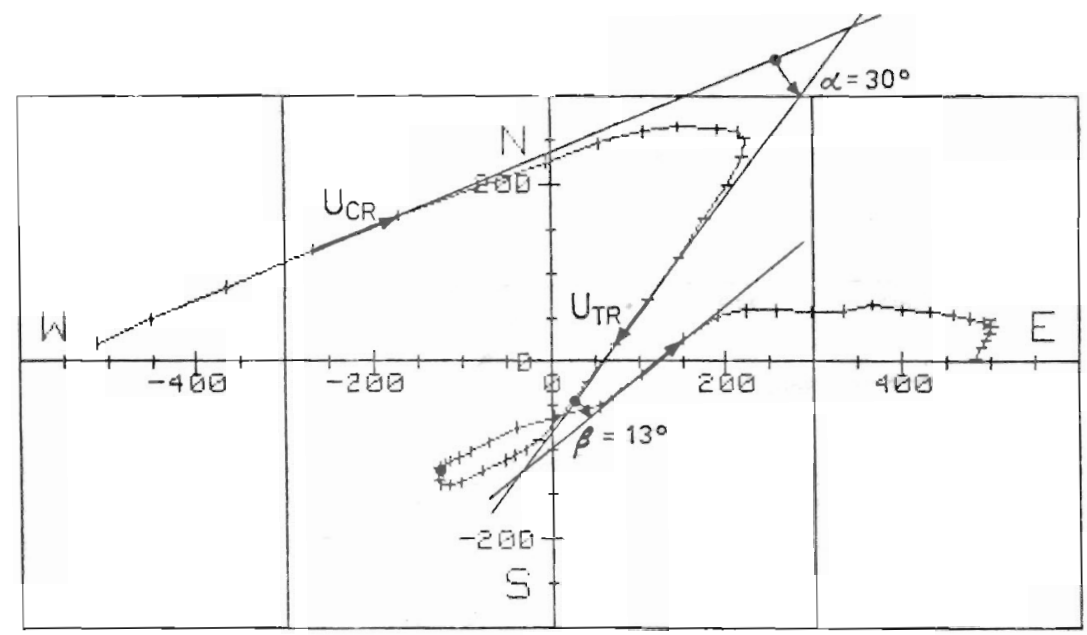

TRACE OF SUCCESEIVE VELOCITY VECTORS

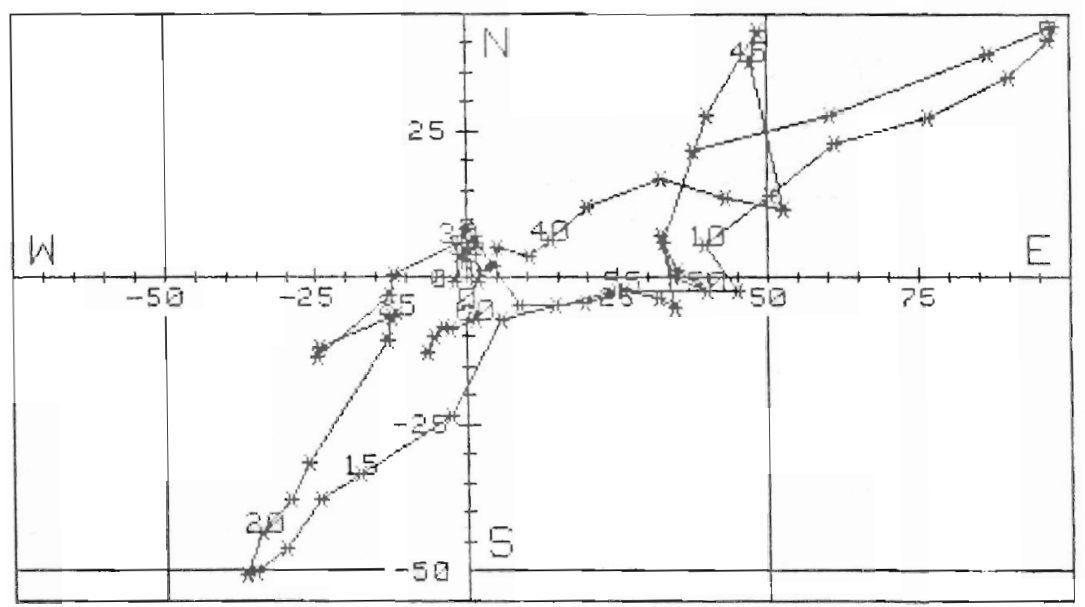

\section{VARIATION OF VELOCITY VECTORS CUFRENT-METER NO: ?}

Fig. 9: Variation of velocity vectors with wave phase 


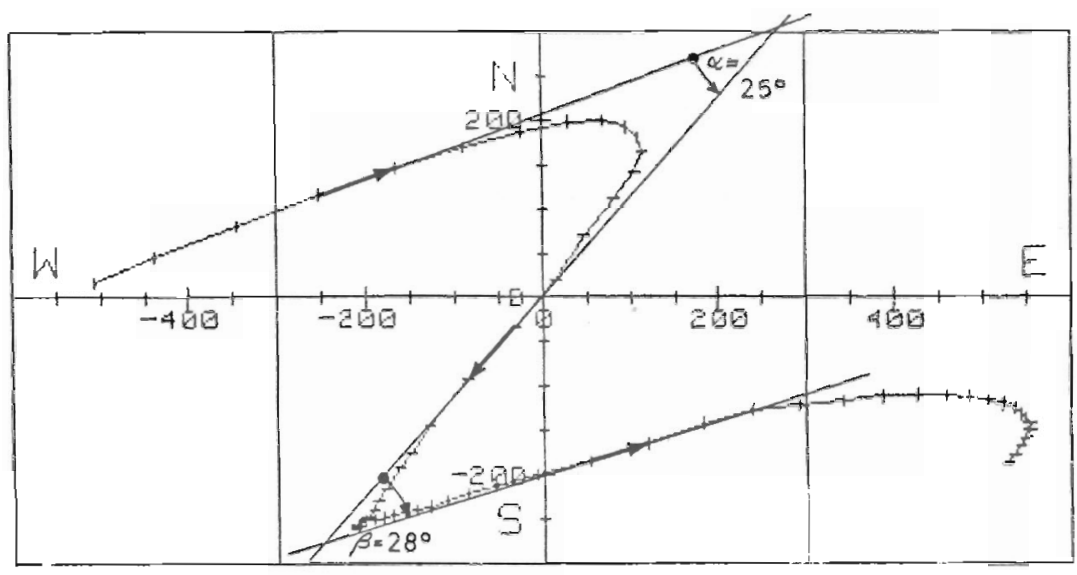

TERCE OF SLCEESEIVE VELOCITY VECTORE

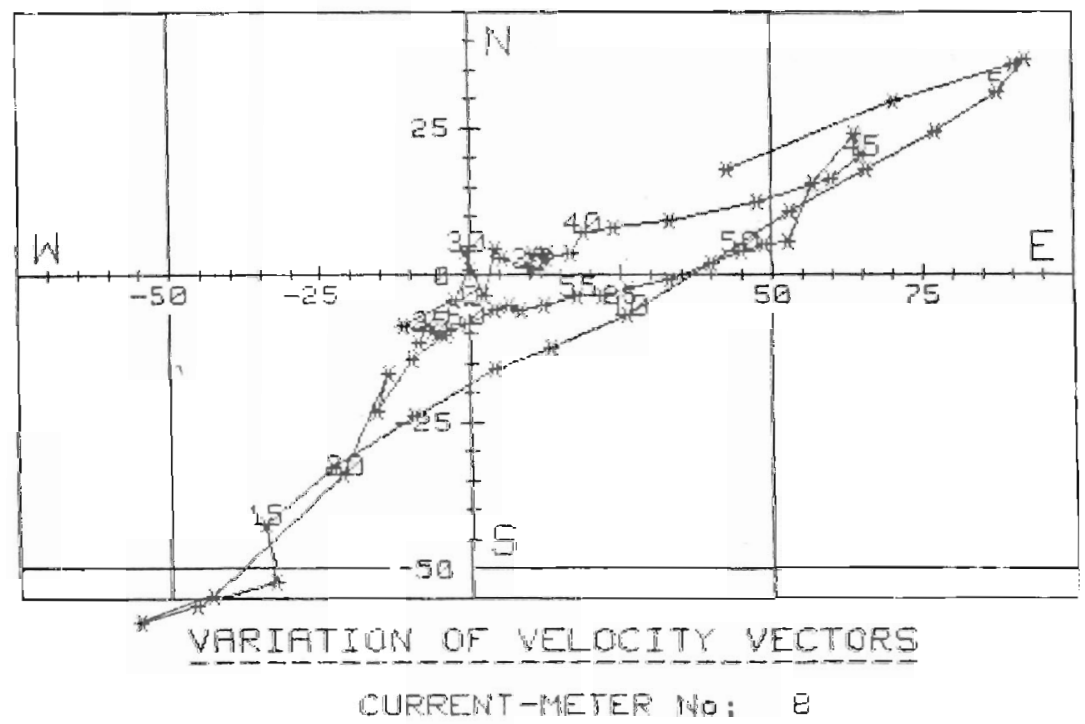

Fig. 10: Variation of velocity vectors with waye phase 


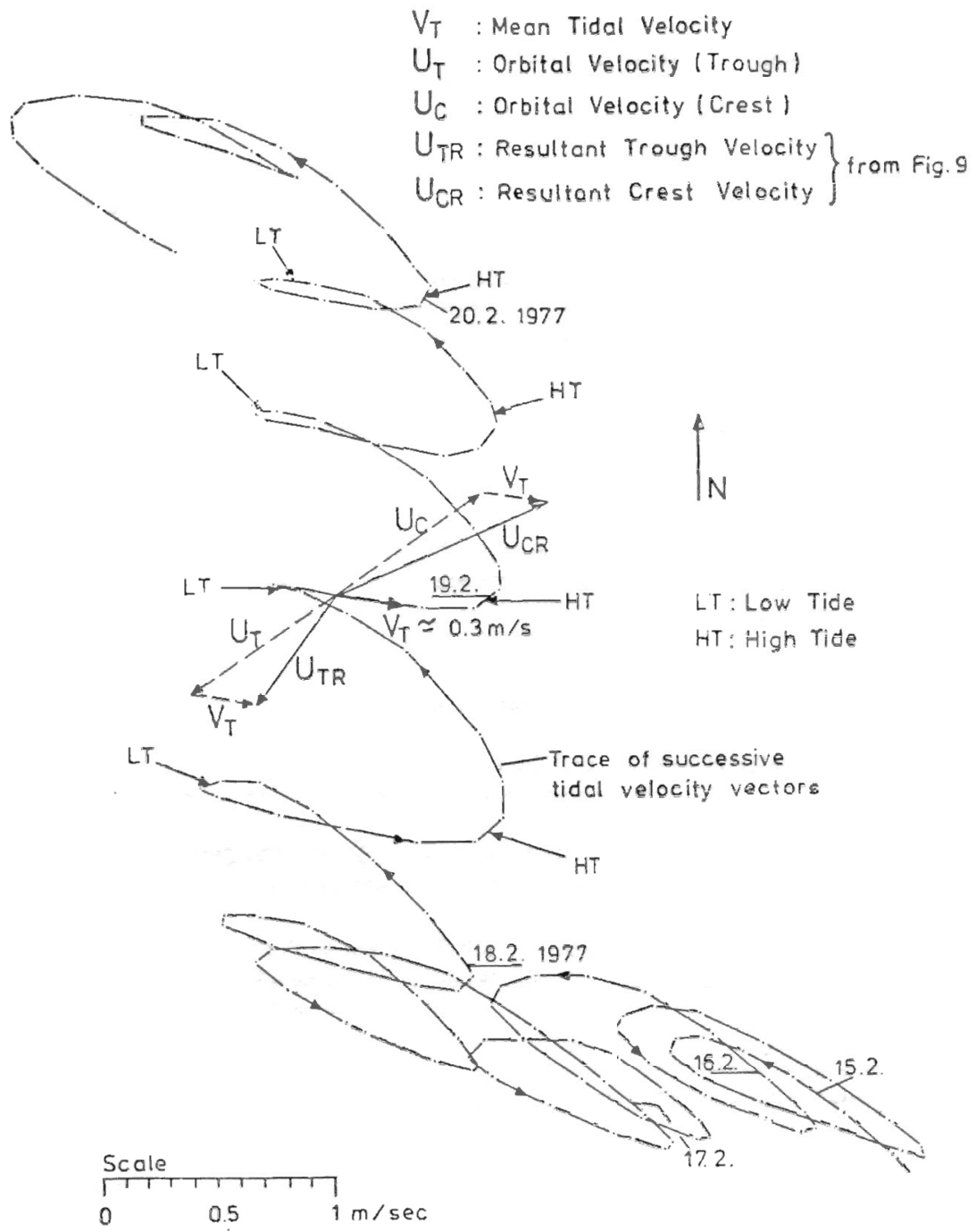

Fig. 11: Variation of tidal stream vectors from February 15th to 20th, 1977 
is (more) sensitive to an asymmetric flow condition resulting in an amplification of the force creating processes.

The evaluations shall be continued in the future. In particular, the synchronous measurements, reparted here, shall be compared to the actual tidal velocify as calculated from the long term velocity mecsurements.

\section{REFERENCES}

BUSCHING, F., MARTINI, E., SPARBOOM, U. (1979)

Measuring Equipment for Field Investigations on Near Surface Wave Forces Proc. BOSS.79, Imperial College, London England

DEAN, R. G. (1976) Methodology for Evaluating Suitability of Wave and Wave Force Data for Determining Drag and Inertia Coefficients. Proceedings of BOSS'76. Norwegian Institute of Technology, Trondheim.

FÜHRBÖTER, A. (1977) Remark on the influence of Wave Spray on Wind Load, Safety of Structures under Dynamic Loading, Vol. 2, Tapir ; Norwegian Inst. of Technology, Trondheim.

HOGBEN, N. (1976) The Wavedozer: A Travelling Beam Wave-maker, Proc. IIth ONR Symposium on Naval Hydrodynamics, London.

HOLMES, P., TICKELL, R. G. (1979) Full Scale Wave Loading on Cylinders. Proc. BOSS' 79, Imperial College, London, England.

KIM, Y. Y., HIBBARD, H.C. (1976) Analysis of Simultaneous Wave Force and Water Particle Velocity Measurement, Paper 2192, OTC.

LONGREE, W.-D. (1976) Aspects of the Instrumentation and Measurement Performances of the Research Platform NORDSEE, Proc. BOSS' 76, Norwegian Inst. of Technology, Trondheim.

PEARCEY, H. H., BISHOP, J.R. (1979) Wave Loading in the Drag and Drag Inerta Regimes; Routes to Design Data, Proc. BOSS'79, Imperial College, London, England.

SARPKAYA, T. (1976) Vortex Shedding and Resistance in Harmonic Flow about Smooth and Rough Circular Cylinders. Proceeding of BOSS'76, Norwegion Instirute of Technology, Trondheim.

YAMAMOTO, T., NATH, J.H. (1976) Hydrodynamic Forces on Groups of Cylinders, OTC 2499. 